\title{
Erratum to: Distal junctional kyphosis in patients with Scheuermann's disease: a retrospective radiographic analysis
}

\author{
Amir Ghasemi ${ }^{1}$ Timo Stubig ${ }^{2}$ Luigi Aurelio Nasto ${ }^{1} \cdot$ Malik Ahmed $^{1}$. \\ Hossein Mehdian ${ }^{1}$
}

Published online: 13 February 2017

(c) Springer-Verlag Berlin Heidelberg 2017

\section{Erratum to: Eur Spine J}

\section{DOI 10.1007/s00586-016-4924-3}

Unfortunately, the given name and family name of the third author was incorrectly tagged in the $\mathrm{xml}$ data, therefore it is abbreviated wrongly as "A Nasto L" in Pubmed. The correct given name is Luigi Aurelio and family name is Nasto.

The online version of the original article can be found under doi:10.1007/s00586-016-4924-3.

$\triangle$ Amir Ghasemi

amir.ghasemi@nuh.nhs.co.uk

1 Center for Spinal Studies, Queens Medical Center, Nottingham University, Derby Road, Nottingham NG7 2UH, UK

2 Trauma Center, Medical School Hannover, Hannover, Germany 